\title{
Review
}

\section{Urinary Tract Infection in Parkinson's Disease}

\author{
Elliot Hogg ${ }^{\mathrm{a}}$, Samuel Frank ${ }^{\mathrm{a}}$, Jillian Oft ${ }^{\mathrm{b}}$, Brian Benway ${ }^{\mathrm{c}}$, \\ Mohammad Harun Rashid ${ }^{\mathrm{a}}$ and Shouri Lahiri ${ }^{\mathrm{d}, *}$ \\ ${ }^{a}$ Department of Neurology, Cedars-Sinai Medical Center, Los Angeles, CA, USA \\ ${ }^{\mathrm{b}}$ Department of Infectious Diseases, Cedars-Sinai Medical Center, Los Angeles, CA, USA \\ ${ }^{\mathrm{c}}$ Department of Urology, Cedars-Sinai Medical Center, Los Angeles, CA, USA \\ ${ }^{\mathrm{d}}$ Departments of Neurology, Neurosurgery, and Biomedical Sciences, Cedars-Sinai Medical Center, Los Angeles, \\ CA, USA
}

Accepted 26 January 2022

Pre-press 8 February 2022

\begin{abstract}
Urinary tract infection (UTI) is a common precipitant of acute neurological deterioration in patients with Parkinson's disease (PD) and a leading cause of delirium, functional decline, falls, and hospitalization. Various clinical features of PD including autonomic dysfunction and altered urodynamics, frailty and cognitive impairment, and the need for bladder catheterization contribute to an increased risk of UTI. Sepsis due to UTI is a feared consequence of untreated or undertreated UTI and a leading cause of morbidity in PD. Emerging research suggests that immune-mediated brain injury may underlie the pathogenesis of UTI-induced deterioration of PD symptoms. Existing strategies to prevent UTI in patients with PD include use of topical estrogen, prophylactic supplements, antibiotic bladder irrigation, clean catheterization techniques, and prophylactic oral antibiotics, while bacterial interference and vaccines/immunostimulants directed against common UTI pathogens are potentially emerging strategies that are currently under investigation. Future research is needed to mitigate the deleterious effects of UTI in PD.
\end{abstract}

Keywords: Parkinson's disease, urinary tract infection, delirium, falls, exacerbation

\section{INTRODUCTION}

Urinary tract infection (UTI) is a leading cause of acute hospitalization in patients with Parkinson's disease (PD) $[1,2]$. In this comprehensive review, we summarize research related to the epidemiology, clinical impact, and pathogenesis of UTI in PD. We further provide a detailed review of current and emerging management strategies to mitigate the risk of UTI-induced neurological deterioration in patients with PD.

\footnotetext{
${ }^{*}$ Correspondence to: Shouri Lahiri, MD, Departments of Neurology, Neurosurgery, and Biomedical Sciences, Cedars-Sinai Medical Center, 8700 Beverly Blvd., Los Angeles, CA 90048, USA. E-mail: Shouri.Lahiri@csmc.edu.
}

\section{EPIDEMIOLOGY AND CLINICAL IMPACT}

Patients with PD are twice as likely to be admitted for UTI compared to non-PD controls $(48.6 \%$ vs. $23.3 \%, p<0.001)$ [3]. Although the risk of UTI increases with age and is generally more common in women, PD-associated UTI occurs in relatively equal proportions between older men and women, consistent with the notion that PD, and the secondary effects inherent to the disease, supersede sex as a risk factor for UTI [1]. PD-associated UTI is likely underreported, as it is often classified as a urinary disorder rather than as an infection [2]. Furthermore, the reason for hospitalization in patients with PD and UTI may be categorized under a related incident, such as 
a fall secondary to UTI, rather than the UTI itself $[4,5]$, thus underestimating the actual incidence and significance of PD-associated UTI. PD is the second most common neurodegenerative condition after Alzheimer's disease and is the fastest growing neurologic condition overall [6]. With PD cases expected to double by 2030 [7], PD-associated UTI is expected to only increase in importance to health care providers and planners in the coming decades.

UTI is a leading cause of acute hospitalization in patients with PD $[8,9]$. Even when not the primary cause for admission, UTIs are often found incidentally at higher rates in patients with PD compared to the general population [10]. Patients with PD who undergo surgeries, both elective and emergency, are also known to be at higher risk of UTI [11]. In one review of nine retrospective studies of 433 patients with PD, UTI was reported to be one of the most frequent orthopedic postoperative complications, in frequencies up to $49 \%$ [12]. The risk of UTI is elevated in patients with PD following total hip arthroplasty $(\mathrm{OR}=1.39 ; 95 \% \mathrm{CI}, 1.09-1.76$; $\mathrm{p}=0.007)[11,13]$, while one-third of patients with PD develop UTI after total knee arthroplasty [13, 14]. These studies highlight the particular risk PD patients undertake when undergoing operative admissions. As UTI-induced motoric dysfunction in PD likely contributes to an increased risk of falls [15] and PD-associated bladder dysfunction increases the risk of UTI, future studies are necessary to clarify the exact directionality of the relationship between UTI and orthopedic injury. Regardless, whether the admission is due to medical or surgical reasons, UTI is a common driver of hospitalization.

Overall, systemic infection is the single most frequent underlying cause for motoric exacerbation in PD, accounting for $25 \%$ of exacerbations [16]. UTI and pneumonia are the most frequently implicated systemic infections that contribute to worsening motoric function [12, 17-20]. This deterioration is significant, with nearly one-third of patients discharging with worse motor function with a mean increase of more than 5 points on the UPDRS-III [20]. Worse motor outcomes lead to increased long-term care placement, increasing the risk for subsequent UTI [21] and potentially leading to a vicious cycle of infection and deterioration. Cognitive deterioration can be equally deleterious and patients with PD and UTI have an increased susceptibility to developing delirium, which may explain why patients with PD have, on average, longer hospital stays than patients without PD (17.8 days vs. 15.4 days, $p<0.001)$
$[3,22]$. UTI is also associated with psychosis in PD, which increases the risk for subsequent nursing home care [8].

Sepsis due to UTI, often from Escherichia coli, Streptococcus spp., and Klebsiella pneumoniae, is a feared consequence of untreated or undertreated UTI and a leading cause of morbidity in PD [3, 23]. There is a clear increase in the trend of PD patients being admitted with unspecified sepsis and UTI [7], which is of concern as PD patients are twice as likely to stay in the hospital for longer than 3 months. Additionally, PD hospital mortality rates are 1.5 times higher than controls $(3.9 \%$ vs. $2.5 \%)$ in the US [7, 24] and 2.5 times higher in the UK $[25,26]$. These factors combine to increase the need for new interventions for PD-related UTI as demographic and epidemiologic factors are driving a massive increase in the burden of this treatable disease on an already overtaxed healthcare system.

\section{RISK FACTORS}

Patients with PD are susceptible to UTI due to several modifiable and non-modifiable risk factors (Fig. 1). In this section, we will explore underlying risk factors that increase the risk of UTI in PD.

\section{Disease progression, care-setting, and dementia}

Several clinical features of PD account for the increased risk of UTI, including both progressive motor and non-motor dysfunction and, in particular, autonomic nervous system dysfunction. Autonomic dysfunction of the bowel, for example can lead to constipation, fecal impaction, urinary retention and UTI [27] and can also directly impact the urinary system by precipitating neurogenic bladder [28]. Death of dopaminergic neurons in the substantia nigra and the ventral tegmental area are thought to degrade the frontal-basal ganglia D1 dopaminergic circuit, thereby impairing suppression of the micturition reflex and causing loss of bladder control, compounding the risk of UTI [29]. The severity of urinary symptoms, in particular storage symptoms, has been associated with greater nigrostriatal dopaminergic degeneration in early PD [29]. Lower [123I]-FP-CIT SPECT binding in the non-dominant putamen ipsilateral to the side of greater motor deficit has been associated with worse storage symptoms $(\mathrm{r}=-0.172$, $p=0.004)$ and worse voiding symptoms $(\mathrm{r}=-0.119$, $\mathrm{p}=0.049$ ), while severity of bladder dysfunction correlates with degeneration of the caudate [30]. 


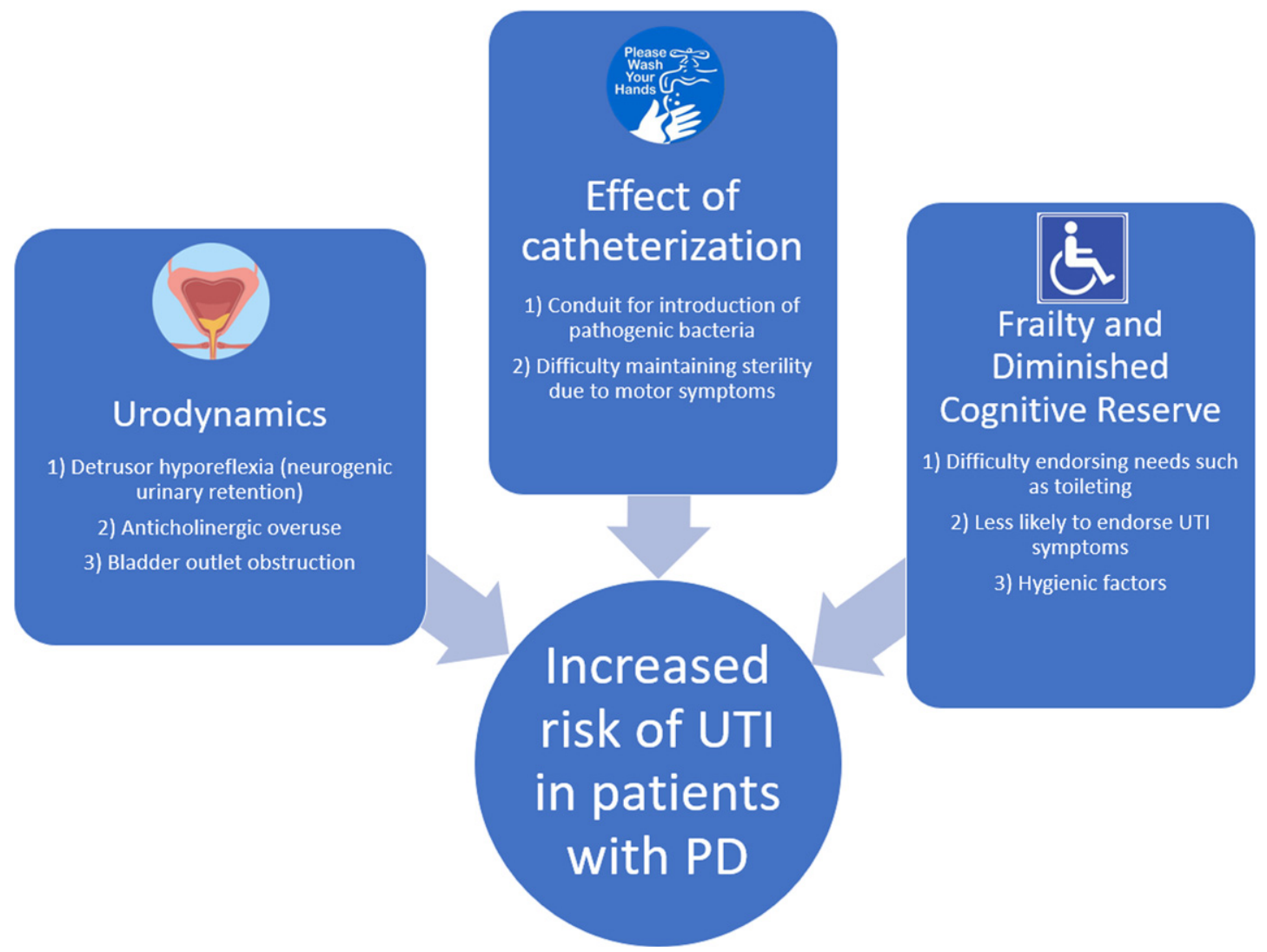

Fig. 1. Risk factors for UTI in Parkinson's disease.

PD-related dementia increases the risk of inadequate self-hygiene, and likelihood of urinary catheterization [31], which can contribute to persistent bacteriuria and lower the threshold for UTI [31]. PD patients, especially those with advanced disease and dementia, are often housed in long-term care facilities where antibiotic resistant bacteria are common [32, 33]. Decreased physical ability, overall poorer health, and reduced ability to perform self-care further increase the risk of UTI $[34,35]$ and compound over the course of the disease, rising with disease duration and severity $[8,36]$. However, the relationship between PD-related cognitive impairment and risk of UTI is complex. First, PDrelated cognitive impairment is associated with more severe Hoehn and Yahr disease stage [37], making confounding variables likely in any retrospective analysis. One recent study of 58,000 patients diagnosed with UTI in the ED controlled for age, sex, catheter use, recurrent UTI and SNF residence, found that patients with dementia are more than twice as likely to be diagnosed with UTI versus those without dementia [38]. However, this study did not categorize type and severity of dementia, the presence of urinary/fecal incontinence or mobility status.

In practice, patients with cognitive impairment may have difficulty endorsing symptoms typically associated with UTI. This may lead to an overdiagnosis of UTI and overtreatment of asymptomatic bacteriuria in the acute setting. On the other hand, this relationship could be causal and cognitive impairment may be an independent risk factor for UTI due to more issues with poor hygiene and infection control. In the second circumstance, PD-related cognitive impairment and its hygienic sequelae may be potentially modifiable risk factors that can be pre-emptively addressed in the outpatient setting. Although formal studies on this topic are lacking, from a practical standpoint the combined motor, dysautonomic, and cognitive burden of PD can be expected to place patients at a higher risk of UTI than in patients with cognitive decline alone; however, more research is needed on the association between PD-related dementia and UTI versus other types of 
dementia and, in particular, to the discrete physiological risks of UTI in PD compared to other etiologies of dementia.

\section{Urodynamics}

Incomplete bladder emptying results in urinary retention and stasis which can predispose to bacteriuria and UTI $[39,40]$. In the context of neurologic disorders, this is termed neurogenic urinary retention. Detrusor hyporeflexia and detrusor-sphincter dyssynergia are two principal mechanisms by which patients can develop neurogenic urinary retention $[41,42]$ yet surprisingly, these two findings are rather uncommon in urodynamic studies of patients with PD, with reported rates of detrusor hyporeflexia ranging from $0-16 \%$ and dyssynergia from $0-3 \%$ [43-46]. When present in patients with $\mathrm{PD}$, it may be associated with advanced disease [46] or the use of anticholinergic medications. In contrast, neurogenic urinary retention is highly prevalent in multiple system atrophy and can be used to distinguish it from PD in atypical cases of Parkinsonism [47, 48].

Detrusor overactivity due to a neurologic disorder is termed "neurogenic detrusor overactivity" and results in storage symptoms including urinary urgency and urge incontinence. Neurogenic detrusor overactivity is the most common cystometric abnormality in PD and is estimated to occur in 45-95\% of patients with $\mathrm{PD}$, with higher frequency in older patients with worse motor and autonomic involvement [46, 49-51]. It is theorized that dopaminergic cell loss in the basal ganglia leads to loss of D1mediated inhibition of the pontine-sacral micturition pathway and subsequent detrusor overactivity [49, 52]. This can lead to a "spastic" bladder that contracts at low volumes, which clinically presents as nocturia, urinary frequency and urgency. These symptoms are the most common urologic complaints in patients with PD and are usually treated with anticholinergics, such as solifenacin [53, 54], as first-line therapy, which can inadvertently increase the risk of UTI [55].

Bladder outlet obstruction is important to consider as an alternative cause of irritative lower urinary tract symptoms in patients with PD because it can mimic neurogenic detrusor overactivity and predispose to UTI and nephropathy. Antimuscarinic drugs may mask the urgency symptoms in these patients but worsen the underlying urinary retention and increase the risk of UTI. Obtaining a post-void residual before prescribing antimuscarinics can help distinguish these two syndromes in patients with PD [56] and referral for urodynamic testing is suggested in patients with complicated lower urinary tract symptoms or those who fail to respond to first-line therapy with anticholinergics [57].

\section{Effect of catheterization}

Urinary catheterization can introduce pathogenic bacteria into the normal urinary bacterial microbiome and cause local mucosal injury, which can predispose to catheter-associated UTI. The need for catheterization in patients with neurogenic urinary retention predisposes many patients with PD to UTI. It is well-known that long-term catheterization is a major risk factor for catheter-associated UTI [58]. In cases where catheterization is necessary in patients with $\mathrm{PD}$, intermittent straight catheterization is preferred. One recent meta-analysis of 2321 patients with neurogenic bladder, independent of PD, suggested that use of intermittent straight catheterization is associated with lower rates of UTI compared to indwelling urinary catheterization $[59,60]$. However, depending on the severity of their motor symptoms, it may be difficult for patients with PD to maintain sterility while performing self-catheterization and they may require caregiver assistance to maintain sterility even in the early stages of disease. To our knowledge, there are no available data comparing rates of UTI in patients with PD who use intermittent straight catheterization versus indwelling urinary catheterization. Further research is needed in the area.

\section{Frailty and urinary retention}

Immobility in patients with PD likely plays a large role in the development of urinary retention and associated UTI. A large retrospective study of over one million female Medicare beneficiaries showed that a diagnosis of urinary retention was positively associated with spinal cord injury, MS and "frailty" [61], a category which includes patients with PD, other neurodegenerative disorders and nursing home residents. Patients diagnosed with urinary retention were 2.5 to 4.5 times more likely to have one or more of these underlying conditions [62]. As expected, a history of UTI was also associated with a diagnosis of urinary retention. Interestingly, patients with frailty and retention did not have a significantly higher rate of catheterization than the total population of patients with retention. This suggests that the higher rate of UTI in PD patients may not be fully explainable by higher rates of catheterization. Rather, immobility 
and mild or sub-clinical urinary retention may be independent risk factors for development of UTI in this population. Araki et al. demonstrated a positive correlation between PD severity and post-void residual urine volume [46]. Even asymptomatic retention defined as post-void residual volume $>150 \mathrm{~mL}$ has been associated with higher rates of UTI in a large screening study [63]; however, the risk-benefit balance of active interventions to maintain lower post residual volumes has not been established. Additional research needs to be done to explore how immobility modifies the risk for urinary retention, catheterization and UTI in patients with PD.

\section{PUTATIVE BIOLOGICAL MECHANISMS}

\section{Urinary retention and stasis}

As previously mentioned, advanced PD may predispose to urinary retention through a variety of mechanisms. One Korean study of 197 PD patients found that $8.9 \%$ had increased post-void residual volumes over $100 \mathrm{cc}$, a well-established risk factor for UTI [64]. Another potential mechanism involves motor dysfunction itself, as patients with advanced PD may have severe rigidity/akinesia preventing access to toileting. Additionally, as PD patients may be at higher risk for urinary incontinence, they may be prescribed anticholinergics, which may independently contribute to an increased risk of UTI [55]. Caution should be taken when titrating antimuscarinic agents on patients with advanced PD and PD dementia to avoid the risk of drug-induced urinary retention. PD patients with cognitive impairment and spastic bladder may benefit from timed or prompted voiding to prevent episodes of urinary incontinence and avoid the need for antimuscarinic therapy, as discussed in further detail below under Management strategies to prevent UTI in PD.

\section{Introduction of bacteria via catheterization}

Indwelling urinary catheterization provides a direct pathway for pathogenic bacteria to ascend from the external environment to the lower urinary tract. There are three possible mechanisms by which catheterization may lead to bacterial colonization of the lower urinary tract and subsequent infection [65-67]. First, bacteria may be introduced directly during catheter insertion if aseptic technique is not observed. Secondly, bacteria may travel along the outside of the catheter, between the urethral mucosa and the exterior of the catheter. Lastly, bacteria may ascend directly along the interior lumen of the catheter. Overall, extraluminal tracking of bacteria seems to be the predominant pathophysiologic mechanism of catheter-associated UTI [67], with biofilm formation playing a role in some cases [68]. Bacteriuria is virtually guaranteed with indwelling urinary catheterization and is more likely with prolonged duration of catheterization.

\section{Pathogenesis of urinary tract infection in $P D$}

The pathogenesis of UTI is complex and depends on multiple factors involving both the host and pathogen. Even a healthy person's urine is not completely sterile, so various host factors likely contribute towards the pathogenesis of UTI. Age, sex, host immune function, e.g., immune senescence in elderly patients with PD, and general illness can all predispose to the development of UTI. Additionally, structural abnormalities of the lower urinary tract including calculi, benign prostatic hyperplasia, and pregnancy are associated with increased risk of UTI [69].

The urinary microbiome is an emerging area of study in the development of UTI [70]. Multiple recent studies have demonstrated that the urinary microbiome profiles differ significantly between healthy controls, patients with asymptomatic bacteriuria and those with chronic lower urinary tract symptoms [71-73]. One recent study examined urine samples from patients with neurogenic bladder from spinal cord injury using 16s rRNA sequencing and found that the presence and duration of neurogenic bladder and methods of catheterization are associated with asymptomatic overgrowth of pathologic bacteria in the lower urinary tract [74]. As the duration of neurogenic bladder increased, patients' urinary microbiomes shifted away from commensally present Corynebacterium and Lactobacillus species towards the typical pathogenic Enterococcus and Enterobacterales species. A healthy urinary microbiome may be necessary to control the proliferation of pathogenic bacteria via competition for nutrients or uroepithelial binding sites [75]. In theory, catheterization and antibiotic overuse would disrupt the healthy urinary microbiome and possibly contribute to recurrent UTI. Additionally, pathogen-specific factors may negatively affect patients with PD, as demonstrated in a recent study in MPTP-lesioned mice that demonstrated that oral administration of Proteus mirabilis, a common UTI pathogen, damages dopaminergic 
neurons and worsens motor function [76]. However, it remains unknown whether urinary infection with Proteus mirabilis or related organisms may have a similar neurotoxic effect on PD pathology and phenotype. Despite the potential relevance of the urinary microbiome in patients with PD, we found no PD specific studies on this topic, potentially representing an important research gap and area for future investigations.

\section{UTI-induced neurotoxicity}

Infection is a well-known trigger of acute cerebral dysfunction and has been implicated in the pathogenesis of delirium. Mild infection such as UTI can trigger inflammatory upregulation which is likely a key step in the behavioral alterations seen in delirium. This can occur independently of blood-brain-barrier disruption via endothelial cell signaling and/or via

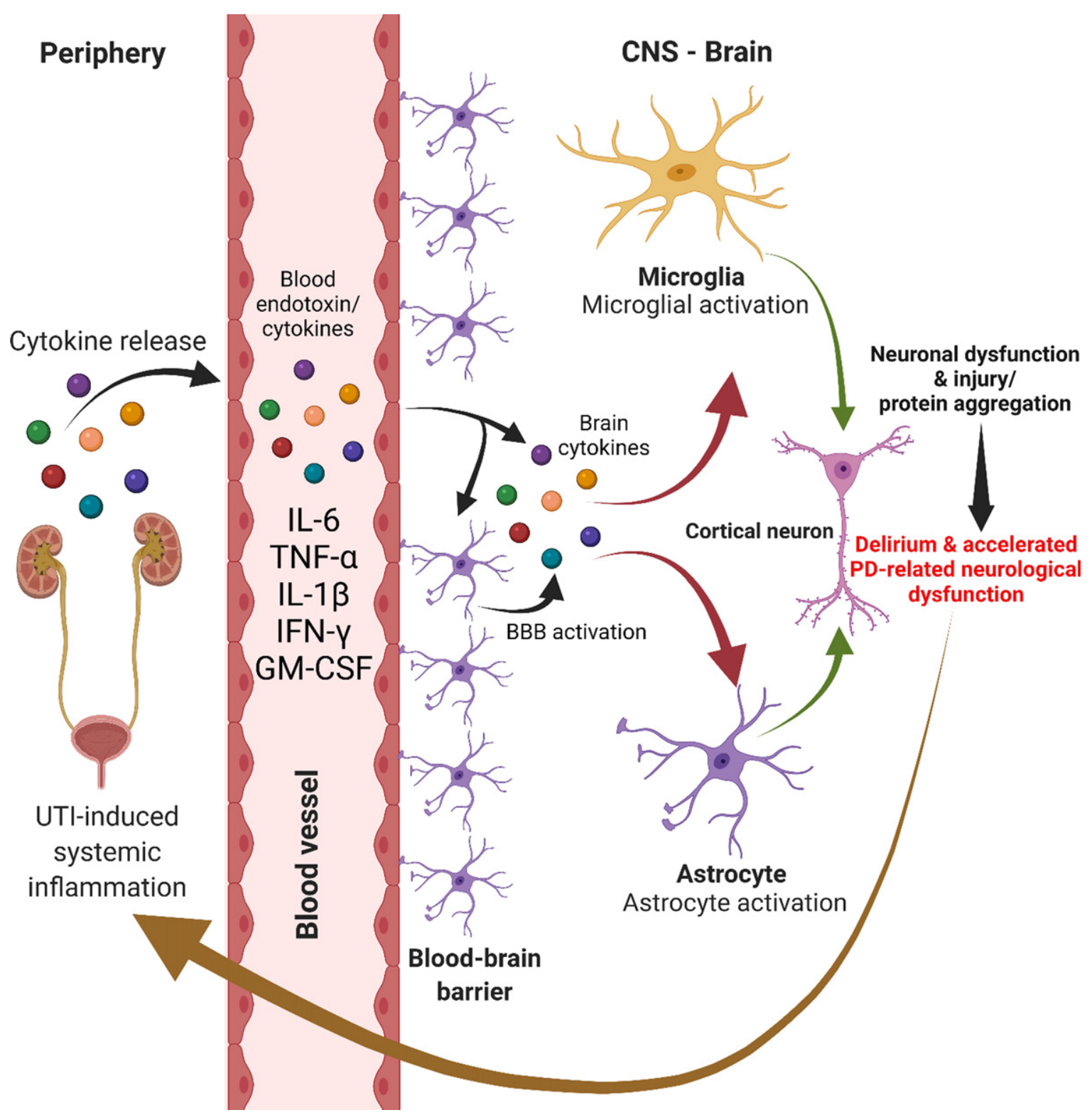

Fig. 2. UTI-induced immune-mediated neurological dysfunction. 
areas without a blood-brain barrier [77]. Animal models of UTI demonstrate that the cytokine interleukin-6 mediates neuronal dysfunction of the frontal cortex and hippocampus leading to delirium-like behavioral states [78]. Indeed, it has been proposed that bacterial endotoxins may interact with aggregable proteins to produce neurodegenerative diseases such as PD [79]. Supporting this theory, endotoxins do appear capable of influencing $\alpha$-synuclein production and aggregation $[80,81]$ and can contribute to substantia nigra dopaminergic neuronal loss $[82,83]$. The possibility that bacterial endotoxins can directly contribute to disease pathogenesis only increases the need for a better understanding of UTI-related neurotoxicity and delirium states (Fig. 2). Indeed, there is evidence that other infections, such as influenza, may precede the diagnosis of PD [84]. Amongst the other studied infections, only urinary tract infection had an increased odds for PD more than 10 years later (increase of 19\% [OR, 1.19; 95\% CI, 1.01-1.40] for urinary tract infection as compared with increase of $73 \%$ [OR, 1.73; 95\% CI, 1.11-2.71] for influenza) [84]. The authors suggest that this could be due to early unrecognized autonomic symptoms of PD increasing the risk for UTI, but given the systemic effects of UTIs, it is possible that UTIs could contribute to PD onset due to neuroinflammatory mechanisms.

Delirium that arises in the context of systemic infections such as UTI is an independent predictor of long-term cognitive decline and dementia [85, 86]. An interesting question can be raised regarding this observation: does this demonstrate a reduced cognitive reserve and reflect "subclinical" dementia, or does delirium result in direct neuronal damage, and can delirium accelerate neurodegeneration? There is a limited amount of observational evidence comparing biomarkers such as S100B [87] and interleukins $[88]$ and brain volumetric analysis $[89,90]$ with and without the presence of delirium. Overall, delirium is associated with higher degrees of inflammation within and outside the CSF, brain atrophy and worse clinical outcomes.

Delirium may have a deleterious impact on clinical outcomes in patients with PD. Two recent review articles found that delirium is associated with worsening cognitive and motor functioning in PD [91, 92]. The biochemical basis of this potentially causative association is unclear but has been explored. Cytokine activation caused by systemic inflammatory stimuli induces degeneration of nigrostriatal dopaminergic neurons in animal models $[93,94]$. The authors in this study posited that abnormally primed microglial cells, in the presence of neurodegeneration, were triggered by the presence of an inflammatory insult to increase translation of pro-inflammatory cytokines, inducing local tissue damage via free radicals and nitric oxide. Could recurrent UTI in the absence of acute delirium predispose to cognitive and functional decline through these same mechanisms? Given the association between UTI and delirium in the PD population, more research is needed on the effect of UTI on long-term clinical outcomes in PD.

\section{MANAGEMENT STRATEGIES TO PREVENT UTI IN PD}

Although there is little in the way of high-quality data to prevent UTI in PD, several measures can be considered as part of a multifaceted approach. In general, all patients with PD and urinary retention should be counseled on maintaining adequate hygiene including perineal cleanliness and, if required, aseptic catheterization techniques (discussed below). In addition, regular scheduled bladder and bowel emptying should be encouraged to reduce urinary retention and inadvertent fecal contamination from stool incontinence. There should be a low threshold to treat

Table 1

Concomitant conditions that lead to recurrent UTI and recommendations for prevention [145]

\begin{tabular}{lc}
\hline $\begin{array}{l}\text { Concomitant } \\
\text { conditions }\end{array}$ & Prevention \\
\hline $\begin{array}{l}\text { Postmenopausal } \\
\text { Intermittent or } \\
\text { indwelling } \\
\text { urinary catheter }\end{array}$ & $\begin{array}{l}\text { Vaginal estrogen } \\
\text { Catheter care, aseptic } \\
\text { Poor bladder } \\
\text { emptying }\end{array}$ \\
$\begin{array}{c}\text { procedure } \\
\text { Benign prostatic } \\
\text { outlet } \\
\text { obstruction }\end{array}$ & facilitate better bladder \\
& emptying \\
& Consider alpha-blockers \\
Diabetes & or 5-alpha reductase \\
& inhibitors until \\
& transurethral resection \\
of the prostate (TURP) & Manage hyperglycemia, \\
Advanced uterine & glucosuria; assess \\
prolapse & bladder emptying \\
Enterovesical & Surgical correction; \\
fistula & vaginal pessary \\
& Consider suppressive \\
Nephrolithiasis & antibiotic until surgical \\
& correction \\
Urethral & Consider stone removal, \\
diverticulum & increased fluid intake \\
& Consider suppressive \\
antibiotic until surgical & correction \\
\hline
\end{tabular}


comorbid medical conditions that increase the risk of urinary retention and UTI, such as benign prostatic hyperplasia or diabetes, and adjustment of medications that promote urinary retention (Table 1). More PD-specific research is urgently needed to address this important issue.

\section{Preventative supplements}

\section{Estrogen}

Estrogen has a key role in modulating the natural defenses of the lower urinary tract against UTI by promoting vaginal colonization with lactobacilli [95] and regulating cell growth and differentiation [96]. In one randomized controlled trial, the incidence of UTI was significantly lower in women who received topical estrogen compared to placebo ( 0.5 versus 5.9 episodes per patient-year $(p<0.001))$. Another multi-center, randomized, open, parallel-group study showed that the cumulative proportion of UTI-free women was significantly higher in the topical estrogen group (45\%) compared to the placebo control group (20\%) $(p=0.008)$ [97]. These findings derived from general populations strongly suggest that topical estrogen may reduce the risk of UTI in women with PD.

\section{Cranberry products}

Though cranberry products are routinely used to prevent UTI, few studies have asserted their beneficial effects $[98,99]$. A meta-analysis of 24 studies showed that compared with placebo, water, or no treatment, cranberry products did not significantly reduce the occurrence of symptomatic UTI (RR $0.86,95 \%$ CI 0.71 to 1.04$)$ [100].

\section{Vitamins and other supplements}

Similarly, although prophylactic supplements such as ascorbic acid (vitamin C), D-mannose, methenamine hippurate, chlorhexidine, and probiotics are widely used to prevent recurrent UTI, support for their use is not as well-established in clinical studies [101]. However, given the relative safety of these measures, they may be reasonable to consider on a case-by-case basis.

Although several studies have attempted to assess the effectiveness of probiotics in preventing recurrent UTI, the data are mixed and controversial in the general patient population [102]. Although there have been a large number of observational studies done on the gut microbiome in PD [103], the same cannot be said for the urinary microbiome. Interestingly, one recent randomized control trial $(n=60)$ demonstrated statistically significant improvement in the MDS-UPDRS and several metabolic biomarkers, including quantitative insulin sensitivity check index, homeostasis model of assessment-estimated insulin resistance, malondialdehyde, total glutathione, and high-sensitivity C-reactive protein, following three months of probiotic consumption [104]. Theoretically, positive changes in the gut and/or urinary microbiome may mediate a decreased neuroinflammatory state as host responses are downregulated. This may potentially manifest in symptom reduction and increased subjective well-being. Further research is needed to improve our understanding of the potentially bidirectional relationship between altered urinary microbiome, increased UTI risk and other clinically relevant outcomes in PD.

\section{Bladder irrigation and clean catheterization}

Bladder irrigation with various solutions such as aminoglycoside, glycosaminoglycans [105], povidone-iodine [106], chlorhexidine solution [107], and saline with acetylcysteine [108] have been advocated as a management strategy for patients with indwelling catheters or those who require intermittent catheterizations [109, 110]. Although several studies have demonstrated the efficacy of bladder irrigation with various agents [111-113], gentamicin remains the best intravesical treatment that has shown efficacy in both the prevention and treatment of recurrent UTIs [114]. Furthermore, the risk of developing antibiotic resistance and systemic adverse effects is low in patients treated with bladder irrigation with gentamicin [115].

Clean intermittent catheterization has been advocated as a quick, safe, and valuable cost-effective technique in combination with other treatment options to prevent recurrent UTI if the post-void residual is consistently more than $100 \mathrm{~mL}[116,117]$. Factors that determine the frequency of catheterizations include fluid intake, urine production, patient motivation, patient and caregiver schedules [109]. Patients and/or caregivers should be trained on the aseptic technique of catheterization: sterile gloves and catheter, non-traumatic urethral insertion, appropriate sterile lubricant, perineal hygiene, etc. An assessment of manual dexterity, anatomical, social and psychological factors is very important for patients with PD to improve adherence and prevent catheter-associated UTIs [118, 119]. Alternative bladder drainage strategies should be considered 
Table 2

Summary of interventions and recommendations from European Association of Urology [120]

\begin{tabular}{|c|c|c|}
\hline Interventions & Recommendation & Notes \\
\hline $\begin{array}{l}\text { Behavioral } \\
\text { modifications }\end{array}$ & $\begin{array}{l}\text { Made despite the absence } \\
\text { of directly applicable } \\
\text { quality clinical studies }\end{array}$ & $\begin{array}{l}\text { Consistently documented the lack of } \\
\text { association with recurrent UTI } \\
\text { [146] }\end{array}$ \\
\hline $\begin{array}{l}\text { Hormonal } \\
\text { replacement }\end{array}$ & Can be recommended & $\begin{array}{l}\text { In postmenopausal women applied } \\
\text { topically but not oral }[137,147]\end{array}$ \\
\hline $\begin{array}{l}\text { Immunoactive } \\
\text { prophylaxis }\end{array}$ & Can be recommended & $\begin{array}{l}\text { Based on studies of OM-89 [148, } \\
\text { 149] }\end{array}$ \\
\hline $\begin{array}{l}\text { Probiotics } \\
\quad \text { (Lactobacillus) }\end{array}$ & No recommendation & $\begin{array}{l}\text { Differences in effectiveness between } \\
\text { available preparations warrant } \\
\text { further trials [102] }\end{array}$ \\
\hline Cranberry & No recommendation & Further trials are warranted [100] \\
\hline D-mannose & No recommendation & Further trials are warranted [150] \\
\hline $\begin{array}{l}\text { Endovesical } \\
\text { instillation }\end{array}$ & No recommendation & $\begin{array}{l}\text { Large-scale trials are urgently needed } \\
\text { [151] }\end{array}$ \\
\hline $\begin{array}{l}\text { Continuous } \\
\text { low-dose } \\
\text { antimicrobial } \\
\text { prophylaxis }\end{array}$ & May be given & $\begin{array}{l}\text { Offer after counseling, and when } \\
\text { behavioral modifications and } \\
\text { non-antimicrobial measures have } \\
\text { been unsuccessful }[121,152]\end{array}$ \\
\hline $\begin{array}{l}\text { Self-diagnosis and } \\
\text { self-treatment }\end{array}$ & $\begin{array}{l}\text { Should be considered in } \\
\text { patients with good } \\
\text { compliance }\end{array}$ & $\begin{array}{l}\text { The choice of antimicrobials-same as } \\
\text { for sporadic acute uncomplicated } \\
\text { UTI [153] }\end{array}$ \\
\hline
\end{tabular}

when patients become severely disabled and incontinence persists resulting in chronic or frequent infections, potentially via suprapubic rather than indwelling catheters [120].

\section{Prophylactic antibiotics}

Prophylaxis with oral antibiotics may be considered in highly selected patients who have frequent recurrent UTIs and in whom conservative measures, including behavioral modifications and non-antimicrobial treatments, have been unsuccessful. A double-blinded randomized clinical study evaluated the efficacy and safety of fosfomycin in the prevention of recurrent UTI and showed a significantly lower number of UTI in the antibiotic compared to the placebo group ( 0.14 vs. 2.97 infections/patient-year; $p<0.001)$ [121]. The potential benefits of a prophylactic antibiotic regimen should be carefully weighed against the risks, including that of producing antibiotic-resistant organisms. Additionally, the dangers of drug-drug interactions and polypharmacy need to be considered carefully. Notably, linezolid, which may be used to treat UTI, can interact with other monoamine oxidase inhibitors such as rasagiline or carbidopa-levodopa [122], and precipitate serotonin syndrome, a feared neuromedical emergency [123, 124]. Ciprofloxacin may also increase plasma levels of ropinirole and exacerbate its adverse effects, such as nausea, dizziness, hallucinations or orthostatic hypotension [125]. A close review of potential medication interactions is warranted prior to initiation of prophylactic antibiotic therapy in patients with PD and recurrent UTIs.

Minocycline has been suggested as possibly neuroprotective in PD by preventing nigrostriatal dopaminergic neurodegeneration in MPTP treated mice $[126,127]$ and has potentially positive effects on gut microbiome in PD [128]; however, animal studies have found mixed results, sometimes showing deleterious effects in PD animal models [129, 130]. Furthermore, minocycline may not be an appropriate UTI prophylactic agent due to increased rates of resistance to common UTI pathogens [131]. Ceftriaxone may also have neuroprotective effects against dopaminergic neuronal injury in 6-hydroxydopamine-lesioned rats [132], while ampicillin has been shown to prevent motor and behavioral impairments in toxic post-streptococcal A murine models and increased tyrosine hydroxylase and D1 and D2 receptors in the striatum [133]. However, no human trials in PD have directly compared the efficacy of these antimicrobial agents, thus limiting any specific recommendations.

\section{Emerging interventions}

\section{Bacterial interference}

Competitive inoculation with commensal or lesspathogenic bacteria is currently under investigation to prevent recurrent UTI. A double-blind randomized crossover trial in patients with incomplete bladder 
emptying and recurrent UTI investigated if the deliberate establishment of asymptomatic bacteriuria with Escherichia coli 83972 reduced rates of UTI recurrence [134]. The study showed that there was a delayed onset of UTI in patients instilled with $E$. coli 83972 in the bladder compared to those who were instilled with saline (median 11.3 vs. 5.7 months; $p=0.0129$ ). Furthermore, there were significantly fewer episodes of UTIs in patients inoculated with E. coli 83972 bacteriuria compared to the saline group (13 vs 35 episodes; $p=0.009$, CI $0.31-$ 1.89). Although the use of less-pathogenic strains of uropathogenic bacteria to compete with and prevent colonization and infection with diseasecausing organisms seems promising, the practicality of achieving sustained colonization with nonpathogenic organisms remains a concern.

\section{Vaccines and immunostimulants}

Recent innovative efforts have been directed towards developing vaccines against uropathogenic organisms. These vaccines are thought to stimulate immune function by activating dendritic cells, neutrophils, and $\mathrm{T}$ helper cells, leading to activation of $\mathrm{T}$ lymphocytes and B lymphocytes and associated IgA-mediated immune protection [135, 136]. OM-89 (Uro-Vaxom) is an oral capsule that is comprised of extracts from 18 strains of heat-killed uropathogenic E. coli and is currently available in Europe to prevent E. coli UTI. A systematic meta-analysis of four randomized, placebo-controlled trials of 891 patients with recurrent UTI showed that OM-89 significantly reduced UTI compared to a placebo group with a relative risk of 0.61 (95\% CI 0.48-0.78) [137]. In preliminary studies, MV140 (Uromune), a sublingually administered vaccine against four common strains of inactivated uropathogens, E. coli, K. pneumoniae, P. vulgaris and E. faecalis, was shown to dramatically reduce the mean number of UTIs at 3 months compared with usual care with antibiotics $(0.36$ versus $1.60 ; p<0.0001)$ [138]. These provocative results await confirmation in follow-up studies.

\section{Identifying and reporting UTI in PD}

Cognitively intact patients with urinary symptoms should have testing with a urinary dipstick as an initial measure to evaluate for the presence of nitrite or leukocyte esterase or, alternatively, a urinalysis to detect pyuria. Although urinary culture is not required in all cases of uncomplicated UTI, it is preferred to document speciation and susceptibility to antibiotics [139]. In cognitively impaired patients in whom self-reporting of urinary symptoms may be limited, an acute change in mental status, with or without localizable genitourinary symptoms, such as dysuria, urgency, or suprapubic pain, should prompt diagnostic testing for UTI [140]. Heightened suspicion for UTI is appropriate when these symptoms occur in combination, as demonstrated in a study of nursing home residents that showed that the combination of dysuria with either a change in the character of the patient's urine or mental status predicted the presence of bacteriuria plus pyuria in $63 \%$ of cases [141]. In the future, new technologies may evolve to allow for serial monitoring or automated detection of UTI, perhaps with the use of smart-diapers with built in urinalysis capability [142].

The accurate reporting of UTI in patients with PD is essential to enable assessment of its epidemiological impact. To minimize underestimation of UTI in PD, special care is justified in documenting UTI as a principal cause of admission, rather than as a urinary disorder [143] or urinary dysfunction [144] or to attribute the cause of admission to a consequence of UTI, such as a fall [2].

\section{CONCLUSION}

UTI is a leading cause of hospitalizations, morbidity, and mortality in patients with PD. PD is the fastest growing neurological condition and increases the risk of UTI due to a combination of urodynamic factors, cognitive decline, frailty, catheterization, and exposure to antibiotic resistant organisms in longterm care settings. UTI prevention strategies include the use of protective supplements, in particular estrogen, prophylactic treatments with oral antibiotics, bladder irrigation, and clean intermittent catheterization, while emerging strategies such as competitive inoculation and vaccine-based immunomodulatory interventions are currently being investigated. Substantial research efforts are needed to develop specific interventions that mitigate the burden of PDassociated UTI in human suffering and health care resource expenditure.

\section{CONFLICT OF INTEREST}

American Academy of Neurology Institute (S.L.), F. Widjaja Foundation (S.L.) 


\section{REFERENCES}

[1] Braga M, Pederzoli M, Antonini A, Beretta F, Crespi V (2014) Reasons for hospitalization in Parkinson's disease: a case-control study. Parkinsonism Relat Disord 20, 488492; discussion 488.

[2] Okunoye O, Kojima G, Marston L, Walters K, Schrag A (2020) Factors associated with hospitalisation among people with Parkinson's disease - A systematic review and meta-analysis. Parkinsonism Relat Disord 71, 66-72.

[3] Su CM, Kung CT, Chen FC, Cheng HH, Hsiao SY, Lai YR, Huang CC, Tsai NW, Lu CH (2018) Manifestations and outcomes of patients with Parkinson's disease and serious infection in the emergency department. Biomed Res Int 2018, 6014896.

[4] Queen V (2017) Caring for patients with Parkinson's disease in general hospital settings. Nurs Older People 29, 30-37.

[5] Ostaszkiewicz J, Hornby L, Millar L, Ockerby C (2010) The effects of conservative treatment for constipation on symptom severity and quality of life in communitydwelling adults. $J$ Wound Ostomy Continence Nurs 37, 193-198.

[6] Dorsey ER, Bloem BR (2018) The Parkinson pandemic-a call to action. JAMA Neurol 75, 9-10.

[7] Mahajan A, Balakrishnan P, Patel A, Konstantinidis I, Nistal D, Annapureddy N, Poojary P, Nadkarni GN, Sidiropoulos C (2016) Epidemiology of inpatient stay in Parkinson's disease in the United States: Insights from the Nationwide Inpatient Sample. J Clin Neurosci 31, 162-165.

[8] Factor SA, Feustel PJ, Friedman JH, Comella CL, Goetz CG, Kurlan R, Parsa M, Pfeiffer R, Parkinson Study Group (2003) Longitudinal outcome of Parkinson's disease patients with psychosis. Neurology 60, 1756-1761.

[9] Segal O, Hassin-Baer S, Rosman M, Segal G (2015) Decreased dopaminergic treatment of hospitalized Parkinson's disease patients during infectious diseases is associated with poor outcomes. J Clin Neurosci 22, 12721274.

[10] Bliemel C, Buecking B, Hack J, Aigner R, Eschbach DA, Ruchholtz S, Oberkircher L (2017) Urinary tract infection in patients with hip fracture: An underestimated event? Geriatr Gerontol Int 17, 2369-2375.

[11] Penrose CT, Bala A, Dekker TJ, Seyler TM, Randell TR, Green CL, Wellman SS, Bolognesi MP (2019) Total hip arthroplasty in patients with Parkinson's disease. Duke Orthopedic J 9, 60-67.

[12] Gerlach OH, Winogrodzka A, Weber WE (2011) Clinical problems in the hospitalized Parkinson's disease patient: systematic review. Mov Disord 26, 197-208.

[13] Newman JM, Sodhi N, Wilhelm AB, Khlopas A, Klika AK, Naziri Q, Kryzak TJ, Higuera CA, Mont MA (2019) Parkinson's disease increases the risk of perioperative complications after total knee arthroplasty: a nationwide database study. Knee Surg Sports Traumatol Arthrosc 27, 2189-2195.

[14] Vince KG, Insall JN, Bannerman CE (1989) Total knee arthroplasty in the patient with Parkinson's disease. J Bone Joint Surg Br 71, 51-54.

[15] Parsons JK, Mougey J, Lambert L, Wilt TJ, Fink HA, Garzotto M, Barrett-Connor E, Marshall LM (2009) Lower urinary tract symptoms increase the risk of falls in older men. BJU Int 104, 63-68.
[16] Zheng KS, Dorfman BJ, Christos PJ, Khadem NR, Henchcliffe C, Piboolnurak P, Nirenberg MJ (2012) Clinical characteristics of exacerbations in Parkinson disease. $\mathrm{Neu}$ rologist 18, 120-124.

[17] Barber M, Stewart D, Grosset D, MacPhee G (2001) Patient and carer perception of the management of Parkinson's disease after surgery. Age Ageing 30, 171-172.

[18] Gerlach OH, Broen MP, van Domburg PH, Vermeij AJ, Weber WE (2012) Deterioration of Parkinson's disease during hospitalization: survey of 684 patients. BMC Neurol 12, 13.

[19] Derry CP, Shah KJ, Caie L, Counsell CE (2010) Medication management in people with Parkinson's disease during surgical admissions. Postgrad Med J 86, 334-337.

[20] Gerlach OH, Broen MP, Weber WE (2013) Motor outcomes during hospitalization in Parkinson's disease patients: a prospective study. Parkinsonism Relat Disord 19, 737-741.

[21] Genao L, Buhr GT (2012) Urinary tract infections in older adults residing in long-term care facilities. Ann Longterm Care 20, 33-38.

[22] Munim F (2017) Management of inpatients with Parkinson's Disease in the acute setting. Geriatr Med J 47.

[23] Behzadi P, Behzadi E, Yazdanbod H, Aghapour R, Akbari Cheshmeh M, Salehian Omran D (2010) A survey on urinary tract infections associated with the three most common uropathogenic bacteria. Maedica (Bucur) 5, 111-115.

[24] Ricciardi R, Roberts PL, Read TE, Baxter NN, Marcello PW, Schoetz DJ (2011) Mortality rate after nonelective hospital admission. Arch Surg 146, 545-551.

[25] Low V, Ben-Shlomo Y, Coward E, Fletcher S, Walker R, Clarke CE (2015) Measuring the burden and mortality of hospitalisation in Parkinson's disease: A cross-sectional analysis of the English Hospital Episodes Statistics database 2009-2013. Parkinsonism Relat Disord 21, 449454.

[26] Clarke CE (2010) Has drug therapy changed the natural history of Parkinson's disease? J Neurol 257, S262-267.

[27] Ostaszkiewicz JSC, Hornby L. (2005) Does successful treatment of constipation or faecal impaction resolve lower urinary tract symptoms: a structured review of the literature. Systematic review. Aust N Z Continence J 11, 70, 72, 74-75, 77-80.

[28] Pannek J, Gocking K, Bersch U (2009) 'Neurogenic' urinary tract dysfunction: don't overlook the bowel! Spinal Cord 47, 93-94.

[29] Wang J, Cao R, Huang T, Liu C, Fan Y (2020) Urinary dysfunction is associated with nigrostriatal dopaminergic degeneration in early and untreated patients with Parkinson's disease. Parkinsons Dis 2020, 4981647.

[30] Winge K, Friberg L, Werdelin L, Nielsen KK, Stimpel H (2005) Relationship between nigrostriatal dopaminergic degeneration, urinary symptoms, and bladder control in Parkinson's disease. Eur J Neurol 12, 842-850.

[31] Rowe TA, Juthani-Mehta M (2013) Urinary tract infection in older adults. Aging Health 9, 10.2217/ahe.13.38.

[32] Loeb M, Brazil K, Lohfeld L, McGeer A, Simor A, Stevenson K, Walter S, Zoutman D (2002) Optimizing antibiotics in residents of nursing homes: protocol of a randomized trial. BMC Health Serv Res 2, 17.

[33] Nicolle LE (2002) Resistant pathogens in urinary tract infections. J Am Geriatr Soc 50, S230-235.

[34] Eberle CM, Winsemius D, Garibaldi RA (1993) Risk factors and consequences of bacteriuria in non-catheterized nursing home residents. J Gerontol 48, M266-271. 
[35] Jamsen E, Puolakka T, Peltola M, Eskelinen A, Lehto MU (2014) Surgical outcomes of primary hip and knee replacements in patients with Parkinson's disease: a nationwide registry-based case-controlled study. Bone Joint J 96-B, 486-491.

[36] Factor SA, Molho ES (2000) Emergency department presentations of patients with Parkinson's disease. Am J Emerg Med 18, 209-215.

[37] Simon-Gozalbo A, Rodriguez-Blazquez C, Forjaz MJ, Martinez-Martin P (2020) Clinical characterization of Parkinson's disease patients with cognitive impairment. Front Neurol 11, 731.

[38] Yourman LC, Kent TJ, Israni JS, Ko KJ, Lesser A (2020) Association of dementia diagnosis with urinary tract infection in the emergency department. J Am Coll Emerg Physicians Open 1, 1291-1296.

[39] Truzzi JC, Almeida FM, Nunes EC, Sadi MV (2008) Residual urinary volume and urinary tract infection-when are they linked? J Urol 180, 182-185.

[40] Brookman-May S, Burger M, Hoschke B, Wieland WF, Kendel F, Gilfrich C, Braun KP, May M (2010) [Association between residual urinary volume and urinary tract infection: prospective trial in 225 male patients]. Urologe A 49, 1163-1168.

[41] Stoffel JT (2017) Chronic urinary retention in multiple sclerosis patients: physiology, systematic review of urodynamic data, and recommendations for care. Urol Clin North Am 44, 429-439.

[42] Abrams P, Cardozo L, Fall M, Griffiths D, Rosier P, Ulmsten U, van Kerrebroeck P, Victor A, Wein A, Standardisation Sub-Committee of the International Continence Society (2002) The standardisation of terminology of lower urinary tract function: report from the Standardisation Sub-committee of the International Continence Society. Neurourol Urodyn 21, 167-178.

[43] Berger Y, Blaivas JG, DeLaRocha ER, Salinas JM (1987) Urodynamic findings in Parkinson's disease. J Urol 138, 836-838.

[44] Sakakibara R, Hattori T, Uchiyama T, Yamanishi T (2001) Videourodynamic and sphincter motor unit potential analyses in Parkinson's disease and multiple system atrophy. J Neurol Neurosurg Psychiatry 71, 600-606.

[45] Stocchi F, Carbone A, Inghilleri M, Monge A, Ruggieri S, Berardelli A, Manfredi M (1997) Urodynamic and neurophysiological evaluation in Parkinson's disease and multiple system atrophy. J Neurol Neurosurg Psychiatry 62, 507-511.

[46] Araki I, Kitahara M, Oida T, Kuno S (2000) Voiding dysfunction and Parkinson's disease: urodynamic abnormalities and urinary symptoms. J Urol 164, 1640-1643.

[47] Hahn K, Ebersbach G (2005) Sonographic assessment of urinary retention in multiple system atrophy and idiopathic Parkinson's disease. Mov Disord 20, 1499-1502.

[48] Fanciulli A, Goebel G, Lazzeri G, Granata R, Kiss G, Strano S, Colosimo C, Pontieri FE, Kaufmann H, Seppi K, Poewe W, Wenning GK (2019) Urinary retention discriminates multiple system atrophy from Parkinson's disease. Mov Disord 34, 1926-1928.

[49] Yeo L, Singh R, Gundeti M, Barua JM, Masood J (2012) Urinary tract dysfunction in Parkinson's disease: a review. Int Urol Nephrol 44, 415-424.

[50] Tsujimura A, Yamamoto Y, Sakoda S, Okuda H, Yamamoto K, Fukuhara S, Yoshioka I, Kiuchi H, Takao T, Miyagawa Y, Nonomura N (2014) Finger taps and constipation are closely related to symptoms of overactive bladder in male patients with Parkinson's disease. Int $J$ Urol 21, 69-73.

[51] Lin FY, Yang YC, Lin CL, Lee LJ (2018) Increased risk of overactive bladder in patients with idiopathic Parkinson's disease: Insight from a nationwide population-based cohort study. PLoS One 13, e0193783.

[52] Blackett H, Walker R, Wood B (2009) Urinary dysfunction in Parkinson's disease: a review. Parkinsonism Relat Disord 15, 81-87.

[53] Zesiewicz TAEM, Vaughan CP, et al. (2015) Randomized, controlled pilot trial of solifenacin succinate for overactive bladder in Parkinson's disease. Parkinsonism Relat Disord 21, 514-520.

[54] Seppi KCK, Coelho M, et al. (2019) Update on treatments for nonmotor symptoms of Parkinson's disease-an evidence-based medicine review. Mov Disord 34, 180-198.

[55] Vouri SM, Kebodeaux CD, Stranges PM, Teshome BF (2017) Adverse events and treatment discontinuations of antimuscarinics for the treatment of overactive bladder in older adults: A systematic review and meta-analysis. Arch Gerontol Geriatr 69, 77-96.

[56] Sakakibara R, Lee FC, Suzuki H, Tateno F, Kishi M, Aiba Y (2018) Parkinson's disease and prostate enlargement: Both contribute to overactive bladder in the elderly. Int $J$ Urol 25, 982-983.

[57] (2019) 2019 surveillance of urinary incontinence in neurological disease: assessment and management (NICE guideline CG148). National Institute for Health and Care Excellence (UK), London.

[58] Li F, Song M, Xu L, Deng B, Zhu S, Li X (2019) Risk factors for catheter-associated urinary tract infection among hospitalized patients: A systematic review and meta-analysis of observational studies. $J$ Adv Nurs $\mathbf{7 5}$, 517-527.

[59] Kinnear N, Barnett D, O’Callaghan M, Horsell K, Gani J, Hennessey D (2020) The impact of catheter-based bladder drainage method on urinary tract infection risk in spinal cord injury and neurogenic bladder: A systematic review. Neurourol Urodyn 39, 854-862.

[60] Siroky MB (2002) Pathogenesis of bacteriuria and infection in the spinal cord injured patient. Am J Med 113(Suppl 1A), 67S-79S.

[61] Hope AA, Gong MN, Guerra C, Wunsch H (2015) Frailty before critical illness and mortality for elderly Medicare beneficiaries. J Am Geriatr Soc 63, 1121-1128.

[62] Cohn JA, Ni S, Kaufman MR, Graves AJ, Penson DF, Dmochowski RR, Reynolds WS (2017) Urinary retention and catheter use among U.S. female Medicare beneficiaries: Prevalence and risk factors. Neurourol Urodyn 36, 2101-2108.

[63] Wu J, Baguley IJ (2005) Urinary retention in a general rehabilitation unit: prevalence, clinical outcome, and the role of screening. Arch Phys Med Rehabil 86, 1772-1777.

[64] Lee YH, Lee JE, Ryu DW, Oh YS, Lee KS, Hong SH, Kim JS (2018) Urinary dysfunctions and post-void residual urine in typical and atypical Parkinson diseases. $J$ Parkinsons Dis 8, 145-152.

[65] Hart JA (1985) The urethral catheter-a review of its implication in urinary-tract infection. Int J Nurs Stud 22, 57-70.

[66] Maki DG, Tambyah PA (2001) Engineering out the risk for infection with urinary catheters. Emerg Infect Dis 7, 342-347.

[67] Tambyah PA, Halvorson KT, Maki DG (1999) A prospective study of pathogenesis of catheter-associated urinary tract infections. Mayo Clin Proc 74, 131-136. 
[68] Nickel JC, Costerton JW, McLean RJ, Olson M (1994) Bacterial biofilms: influence on the pathogenesis, diagnosis and treatment of urinary tract infections. J Antimicrob Chemother 33(Suppl A), 31-41.

[69] Kaye D (1975) Host defense mechanisms in the urinary tract. Urol Clin North Am 2, 407-422.

[70] Perez-Carrasco V, Soriano-Lerma A, Soriano M, Gutierrez-Fernandez J, Garcia-Salcedo JA (2021) Urinary microbiome: yin and yang of the urinary tract. Front Cell Infect Microbiol 11, 617002.

[71] Karstens L, Asquith M, Davin S, Stauffer P, Fair D, Gregory WT, Rosenbaum JT, McWeeney SK, Nardos R (2016) Does the urinary microbiome play a role in urgency urinary incontinence and its severity? Front Cell Infect Microbiol 6, 78 .

[72] Shoskes DA, Altemus J, Polackwich AS, Tucky B, Wang $\mathrm{H}$, Eng C (2016) The urinary microbiome differs significantly between patients with chronic prostatitis/chronic pelvic pain syndrome and controls as well as between patients with different clinical phenotypes. Urology 92, 26-32.

[73] Nickel JC, Stephens A, Landis JR, Mullins C, van Bokhoven A, Lucia MS, Ehrlich GD, Network MR (2016) Assessment of the lower urinary tract microbiota during symptom flare in women with urologic chronic pelvic pain syndrome: A MAPP Network Study. J Urol 195, 356-362.

[74] Fouts DE, Pieper R, Szpakowski S, Pohl H, Knoblach S, Suh MJ, Huang ST, Ljungberg I, Sprague BM, Lucas SK, Torralba M, Nelson KE, Groah SL (2012) Integrated nextgeneration sequencing of $16 \mathrm{~S}$ rDNA and metaproteomics differentiate the healthy urine microbiome from asymptomatic bacteriuria in neuropathic bladder associated with spinal cord injury. J Transl Med 10, 174.

[75] Cortes-Penfield NW, Trautner BW, Jump RLP (2017) Urinary tract infection and asymptomatic bacteriuria in older adults. Infect Dis Clin North Am 31, 673-688.

[76] Choi JG, Kim N, Ju IG, Eo H, Lim SM, Jang SE, Kim DH, Oh MS (2018) Oral administration of Proteus mirabilis damages dopaminergic neurons and motor functions in mice. Sci Rep 8, 1275.

[77] Maclullich AM, Ferguson KJ, Miller T, de Rooij SE, Cunningham C (2008) Unravelling the pathophysiology of delirium: a focus on the role of aberrant stress responses. J Psychosom Res 65, 229-238.

[78] Rashid MH, Sparrow NA, Anwar F, Guidry G, Covarrubias AE, Pang H, Bogguri C, Karumanchi SA, Lahiri S (2021) Interleukin-6 mediates delirium-like phenotypes in a murine model of urinary tract infection. J Neuroinflammation 18, 247.

[79] Brown GC (2019) The endotoxin hypothesis of neurodegeneration. J Neuroinflammation 16, 180.

[80] Kim C, Lv G, Lee JS, Jung BC, Masuda-Suzukake M, Hong CS, Valera E, Lee HJ, Paik SR, Hasegawa M, Masliah E, Eliezer D, Lee SJ (2016) Exposure to bacterial endotoxin generates a distinct strain of alpha-synuclein fibril. Sci Rep 6, 30891 .

[81] Wang W, Nguyen LT, Burlak C, Chegini F, Guo F, Chataway T, Ju S, Fisher OS, Miller DW, Datta D, Wu F, Wu CX, Landeru A, Wells JA, Cookson MR, Boxer MB, Thomas CJ, Gai WP, Ringe D, Petsko GA, Hoang QQ (2016) Caspase-1 causes truncation and aggregation of the Parkinson's disease-associated protein alpha-synuclein. Proc Natl Acad Sci U S A 113, 9587-9592.

[82] Qin L, Liu Y, Hong JS, Crews FT (2013) NADPH oxidase and aging drive microglial activation, oxidative stress, and dopaminergic neurodegeneration following systemic LPS administration. Glia 61, 855-868.

[83] Qin L, Wu X, Block ML, Liu Y, Breese GR, Hong JS, Knapp DJ, Crews FT (2007) Systemic LPS causes chronic neuroinflammation and progressive neurodegeneration. Glia 55, 453-462.

[84] Cocoros NM, Svensson E, Szepligeti SK, Vestergaard SV, Szentkuti P, Thomsen RW, Borghammer P, Sorensen HT, Henderson VW (2021) Long-term risk of Parkinson disease following influenza and other infections. JAMA Neurol 78, 1461-1470.

[85] Davis DH, Barnes LE, Stephan BC, MacLullich AM, Meagher D, Copeland J, Matthews FE, Brayne C, Function MRCC, Ageing S (2014) The descriptive epidemiology of delirium symptoms in a large population-based cohort study: results from the Medical Research Council Cognitive Function and Ageing Study (MRC CFAS). BMC Geriatr 14, 87.

[86] Fong TG, Davis D, Growdon ME, Albuquerque A, Inouye SK (2015) The interface between delirium and dementia in elderly adults. Lancet Neurol 14, 823-832.

[87] van Munster BC, Korevaar JC, Korse CM, Bonfrer JM, Zwinderman AH, de Rooij SE (2010) Serum S100B in elderly patients with and without delirium. Int $J$ Geriatr Psychiatry 25, 234-239.

[88] Adamis D, Lunn M, Martin FC, Treloar A, Gregson N, Hamilton G, Macdonald AJ (2009) Cytokines and IGF$\mathrm{I}$ in delirious and non-delirious acutely ill older medical inpatients. Age Ageing 38, 326-332; discussion 251.

[89] Gunther ML, Morandi A, Krauskopf E, Pandharipande P, Girard TD, Jackson JC, Thompson J, Shintani AK, Geevarghese S, Miller RR, 3rd, Canonico A, Merkle K, Cannistraci CJ, Rogers BP, Gatenby JC, Heckers S, Gore JC, Hopkins RO, Ely EW, VISIONS Investigation, VISualizing Icu SurvivOrs Neuroradiological Sequelae (2012) The association between brain volumes, delirium duration, and cognitive outcomes in intensive care unit survivors: the VISIONS cohort magnetic resonance imaging study. Crit Care Med 40, 2022-2032.

[90] Morandi A, Rogers BP, Gunther ML, Merkle K, Pandharipande P, Girard TD, Jackson JC, Thompson J, Shintani AK, Geevarghese S, Miller RR, 3rd, Canonico A, Cannistraci CJ, Gore JC, Ely EW, Hopkins RO, VISIONS Investigation, VISualizing Icu SurvivOrs Neuroradiological Sequelae (2012) The relationship between delirium duration, white matter integrity, and cognitive impairment in intensive care unit survivors as determined by diffusion tensor imaging: the VISIONS prospective cohort magnetic resonance imaging study. Crit Care Med 40, 2182-2189.

[91] Vardy ER, Teodorczuk A, Yarnall AJ (2015) Review of delirium in patients with Parkinson's disease. J Neurol 262, 2401-2410.

[92] Lawson RA, McDonald C, Burn DJ (2019) Defining delirium in idiopathic Parkinson's disease: A systematic review. Parkinsonism Relat Disord 64, 29-39.

[93] Pott Godoy MC, Tarelli R, Ferrari CC, Sarchi MI, Pitossi FJ (2008) Central and systemic IL-1 exacerbates neurodegeneration and motor symptoms in a model of Parkinson's disease. Brain 131, 1880-1894.

[94] Pott Godoy MC, Ferrari CC, Pitossi FJ (2010) Nigral neurodegeneration triggered by striatal AdIL-1 administration can be exacerbated by systemic IL-1 expression. $J \mathrm{Neu}$ roimmunol 222, 29-39.

[95] Mirmonsef P, Modur S, Burgad D, Gilbert D, Golub ET, French AL, McCotter K, Landay AL, Spear GT (2015) 
Exploratory comparison of vaginal glycogen and Lactobacillus levels in premenopausal and postmenopausal women. Menopause 22, 702-709.

[96] Teng J, Wang ZY, Jarrard DF, Bjorling DE (2008) Roles of estrogen receptor alpha and beta in modulating urothelial cell proliferation. Endocr Relat Cancer 15, 351-364.

[97] Eriksen B (1999) A randomized, open, parallel-group study on the preventive effect of an estradiol-releasing vaginal ring (Estring) on recurrent urinary tract infections in postmenopausal women. Am J Obstet Gynecol 180, 1072-1079.

[98] Kontiokari T, Sundqvist K, Nuutinen M, Pokka T, Koskela M, Uhari M (2001) Randomised trial of cranberrylingonberry juice and Lactobacillus GG drink for the prevention of urinary tract infections in women. BMJ 322, 1571.

[99] Stothers L (2002) A randomized trial to evaluate effectiveness and cost effectiveness of naturopathic cranberry products as prophylaxis against urinary tract infection in women. Can J Urol 9, 1558-1562.

[100] Jepson RG, Williams G, Craig JC (2012) Cranberries for preventing urinary tract infections. Cochrane Database Syst Rev 10, CD001321.

[101] Sihra N, Goodman A, Zakri R, Sahai A, Malde S (2018) Nonantibiotic prevention and management of recurrent urinary tract infection. Nat Rev Urol 15, 750-776.

[102] Schwenger EM, Tejani AM, Loewen PS (2015) Probiotics for preventing urinary tract infections in adults and children. Cochrane Database Syst Rev, CD008772.

[103] Boertien JM, Pereira PAB, Aho VTE, Scheperjans F (2019) Increasing comparability and utility of gut microbiome studies in Parkinson's disease: a systematic review. J Parkinsons Dis 9, S297-S312.

[104] Tamtaji OR, Taghizadeh M, Daneshvar Kakhaki R, Kouchaki E, Bahmani F, Borzabadi S, Oryan S, Mafi A, Asemi Z (2019) Clinical and metabolic response to probiotic administration in people with Parkinson's disease: A randomized, double-blind, placebo-controlled trial. Clin Nutr 38, 1031-1035.

[105] Cicione A, Cantiello F, Ucciero G, Salonia A, Torella M, De Sio M, Autorino R, Carbone A, Romancik M, Tomaskin R, Damiano R (2014) Intravesical treatment with highly-concentrated hyaluronic acid and chondroitin sulphate in patients with recurrent urinary tract infections: Results from a multicentre survey. Can Urol Assoc J 8, E721-E727.

[106] van den Broek PJ, Daha TJ, Mouton RP (1985) Bladder irrigation with povidone-iodine in prevention of urinary-tract infections associated with intermittent urethral catheterisation. Lancet 1, 563-565.

[107] van den Heijkant M, Haider N, Taylor C, Subramaniam R (2011) Efficacy of bladder irrigation and surveillance program in prevention of urinary tract infections and bladder calculi in children with an ileocystoplasty and bladder neck repair. Pediatr Surg Int 27, 781-785.

[108] Cai T, Gallelli L, Meacci F, Brugnolli A, Prosperi L, Roberta S, Eccher C, Mazzoli S, Lanzafame P, Caciagli P, Malossini G, Bartoletti R (2016) The efficacy of umbelliferone, arbutin, and n-acetylcysteine to prevent microbial colonization and biofilm development on urinary catheter surface: results from a preliminary study. J Pathogens 2016, 1590952.

[109] Cox L, Cameron AP (2014) Prevention of urinary tract infection for patients with neurogenic bladder. Curr Bladder Dysfunct Rep 9, 282-288.
[110] Evans A, Godfrey H (2000) Bladder washouts in the management of long-term catheters. Br J Nurs 9, 900-902, 904, 906.

[111] Ramezani F, Khatiban M, Rahimbashar F, Soltanian AR (2018) Efficacy of bladder irrigation in preventing urinary tract infections associated with short-term catheterization in comatose patients: A randomized controlled clinical trial. Am J Infect Control 46, e45-e50.

[112] Cox L, He C, Bevins J, Clemens JQ, Stoffel JT, Cameron AP (2017) Gentamicin bladder instillations decrease symptomatic urinary tract infections in neurogenic bladder patients on intermittent catheterization. Can Urol Assoc J 11, E350-E354

[113] Moussa M, Chakra MA, Papatsoris AG, Dellis A, Dabboucy B, Fares Y (2021) Bladder irrigation with povidone-iodine prevent recurrent urinary tract infections in neurogenic bladder patients on clean intermittent catheterization. Neurourol Urodyn 40, 672-679.

[114] Dray EV, Clemens JQ (2017) Recurrent urinary tract infections in patients with incomplete bladder emptying: is there a role for intravesical therapy? Transl Androl Urol 6, S163-S170.

[115] van Nieuwkoop C, den Exter PL, Elzevier HW, den Hartigh J, van Dissel JT (2010) Intravesical gentamicin for recurrent urinary tract infection in patients with intermittent bladder catheterisation. Int J Antimicrob Agents 36, 485-490.

[116] Batla A, Tayim N, Pakzad M, Panicker JN (2016) Treatment options for urogenital dysfunction in Parkinson's disease. Curr Treat Options Neurol 18, 45.

[117] Pilloni S, Krhut J, Mair D, Madersbacher H, Kessler TM (2005) Intermittent catheterisation in older people: a valuable alternative to an indwelling catheter? Age Ageing 34, 57-60.

[118] Kapoor S, Bourdoumis A, Mambu L, Barua J (2013) Effective management of lower urinary tract dysfunction in idiopathic Parkinson's disease. Int J Urol 20, 79-84.

[119] Seth JH, Haslam C, Panicker JN (2014) Ensuring patient adherence to clean intermittent self-catheterization. Patient Prefer Adherence 8, 191-198.

[120] Bonkat G, Bartoletti R, Bruyère F, Cai T, Geerlings SE, Köves B, Schubert S, Wagenlehner F, Guidelines Associates: Devlies W, Horváth J, Mantica G, Mezei T, Pilatz A, Pradere B, Veeratterapillay R (2021) EAU Guidelines. Edn. presented at the EAU Annual Congress Milan Italy. URL: https://uroweb.org/guidelines/compilationsof-all-guidelines/

[121] Rudenko N, Dorofeyev A (2005) Prevention of recurrent lower urinary tract infections by long-term administration of fosfomycin trometamol. Double blind, randomized, parallel group, placebo controlled study. Arzneimittelforschung 55, 420-427.

[122] Pettit NN, Alonso V, Wojcik E, Anyanwu EC, Ebara L, Benoit JL (2016) Possible serotonin syndrome with carbidopa-levodopa and linezolid. J Clin Pharm Ther 41, 101-103.

[123] Miller DG, Lovell EO (2011) Antibiotic-induced serotonin syndrome. J Emerg Med 40, 25-27.

[124] Hisham M, Sivakumar MN, Nandakumar V, Lakshmikanthcharan S (2016) Linezolid and Rasagiline - A culprit for serotonin syndrome. Indian J Pharmacol 48, 91-92.

[125] DeMaagd G, Philip A (2015) Part 2: Introduction to the pharmacotherapy of Parkinson's disease, with a focus on the use of dopaminergic agents. P T 40, 590-600. 
[126] Du Y, Ma Z, Lin S, Dodel RC, Gao F, Bales KR, Triarhou LC, Chernet E, Perry KW, Nelson DL, Luecke S, Phebus LA, Bymaster FP, Paul SM (2001) Minocycline prevents nigrostriatal dopaminergic neurodegeneration in the MPTP model of Parkinson's disease. Proc Natl Acad Sci U S A 98, 14669-14674.

[127] Garrido-Mesa N, Zarzuelo A, Galvez J (2013) Minocycline: far beyond an antibiotic. Br J Pharmacol 169, 337-352.

[128] Parashar A, Udayabanu M (2017) Gut microbiota: Implications in Parkinson's disease. Parkinsonism Relat Disord 38, 1-7.

[129] Yang L, Sugama S, Chirichigno JW, Gregorio J, Lorenzl S, Shin DH, Browne SE, Shimizu Y, Joh TH, Beal MF, Albers DS (2003) Minocycline enhances MPTP toxicity to dopaminergic neurons. J Neurosci Res 74, 278-285.

[130] Diguet E, Fernagut PO, Wei X, Du Y, Rouland R, Gross C, Bezard E, Tison F (2004) Deleterious effects of minocycline in animal models of Parkinson's disease and Huntington's disease. Eur J Neurosci 19, 3266-3276.

[131] Muratani T, Matsumoto T (2004) Bacterial resistance to antimicrobials in urinary isolates. Int $J$ Antimicrob Agents 24(Suppl 1), S28-31.

[132] Leung TC, Lui CN, Chen LW, Yung WH, Chan YS, Yung KK (2012) Ceftriaxone ameliorates motor deficits and protects dopaminergic neurons in 6-hydroxydopaminelesioned rats. ACS Chem Neurosci 3, 22-30.

[133] Lotan D, Cunningham M, Joel D (2014) Antibiotic treatment attenuates behavioral and neurochemical changes induced by exposure of rats to group a streptococcal antigen. PLoS One 9, e101257.

[134] Sunden F, Hakansson L, Ljunggren E, Wullt B (2010) Escherichia coli 83972 bacteriuria protects against recurrent lower urinary tract infections in patients with incomplete bladder emptying. J Urol 184, 179-185.

[135] Schmidhammer S, Ramoner R, Holtl L, Bartsch G, Thurnher M, Zelle-Rieser C (2002) An Escherichia coli-based oral vaccine against urinary tract infections potently activates human dendritic cells. Urology 60, 521-526.

[136] Van Pham T, Kreis B, Corradin-Betz S, Bauer J, Mauel J (1990) Metabolic and functional stimulation of lymphocytes and macrophages by an Escherichia coli extract (OM-89): in vitro studies. J Biol Response Mod 9, 231-240.

[137] Beerepoot MA, Geerlings SE, van Haarst EP, van Charante NM, ter Riet G (2013) Nonantibiotic prophylaxis for recurrent urinary tract infections: a systematic review and meta-analysis of randomized controlled trials. J Urol 190, 1981-1989.

[138] Lorenzo-Gomez MF, Padilla-Fernandez B, Garcia-Criado FJ, Miron-Canelo JA, Gil-Vicente A, Nieto-Huertos A, Silva-Abuin JM (2013) Evaluation of a therapeutic vaccine for the prevention of recurrent urinary tract infections versus prophylactic treatment with antibiotics. Int Urogynecol $J$ 24, 127-134.
[139] Hooton TM (2012) Clinical practice. Uncomplicated urinary tract infection. $N$ Engl J Med 366, 1028-1037.

[140] D'Agata E, Loeb MB, Mitchell SL (2013) Challenges in assessing nursing home residents with advanced dementia for suspected urinary tract infections. $J$ Am Geriatr Soc 61, 62-66.

[141] Juthani-Mehta M, Quagliarello V, Perrelli E, Towle V, Van Ness PH, Tinetti M (2009) Clinical features to identify urinary tract infection in nursing home residents: a cohort study. J Am Geriatr Soc 57, 963-970.

[142] Sung WH, Cheng CM (2019) Urinalysis for diaperwearing elderly people using a combination of cottonbased diagnostic devices and smartphone-based image analysis. Health Technol 3, 1-5.

[143] Temlett JA, Thompson PD (2006) Reasons for admission to hospital for Parkinson's disease. Intern Med J 36, 524526.

[144] Tan LC, Tan AK, Tjia HT (1998) The profile of hospitalised patients with Parkinson's disease. Ann Acad Med Singap 27, 808-812.

[145] Aslam S, Albo M, Brubaker L (2020) Recurrent urinary tract infections in adult women. JAMA 323, 658-659.

[146] Hooton TM (2001) Recurrent urinary tract infection in women. Int J Antimicrob Agents 17, 259-268.

[147] Raz R, Stamm WE (1993) A controlled trial of intravaginal estriol in postmenopausal women with recurrent urinary tract infections. N Engl J Med 329, 753-756.

[148] Naber KG, Cho YH, Matsumoto T, Schaeffer AJ (2009) Immunoactive prophylaxis of recurrent urinary tract infections: a meta-analysis. Int $J$ Antimicrob Agents 33, 111-119.

[149] Bauer HW, Alloussi S, Egger G, Blümlein HM, Cozma G, Schulman CC (2005) A long-term, multicenter, doubleblind study of an Escherichia coli extract (OM-89) in female patients with recurrent urinary tract infections. Eur Urol 47, 542-548; discussion 548.

[150] Kranjeec B, Papes D, Altarac S (2014) D-mannose powder for prophylaxis of recurrent urinary tract infections in women: a randomized clinical trial. World J Urol 32, 79-84.

[151] Madersbacher H, van Ophoven A, van Kerrebroeck PE (2013) GAG layer replenishment therapy for chronic forms of cystitis with intravesical glycosaminoglycans-a review. Neurourol Urodyn 32, 9-18.

[152] Albert X, Huertas I, Pereiró, II, Sanfélix J, Gosalbes V, Perrota C (2004) Antibiotics for preventing recurrent urinary tract infection in non-pregnant women. Cochrane Database Syst Rev 2004, CD001209.

[153] Schaeffer AJ, Stuppy BA (1999) Efficacy and safety of self-start therapy in women with recurrent urinary tract infections. J Urol 161, 207-211. 